\title{
Proposta de Inserção do Design Social no Trabalho do Designer na EaD
}

\author{
Proposal for Insertion of Social Design in the Work of the Designer in EaD
}

XAVIER, Aline Freitas da Silva; Doutoranda; Universidade do Estado de Minas Gerais(UEMG); Instituto Federal do Espírito Santo (Ifes)

alinegoval@gmail.com

ALMEIDA, Marcelina das Graças de; Doutora; Universidade do Estado de Minas Gerais (UEMG)

almeidamarcelina@gmail.com

SONDERMANN, Danielli Veiga Carneiro; Doutora; Instituto Federal do Espírito Santo (Ifes)

daniellicarneiro@gmail.com

\section{Resumo}

A Educação a Distância (EaD) apresenta-se como uma área para o designer também atuar, ainda pouco explorada, mas com grande potencial de crescimento. Por tudo isso, entende-se que o design social pode vir a ser uma importante ferramenta para o desenvolvimento do trabalho do designer que atua na EaD. Com isso, este artigo objetiva apresentar as diretrizes de design social desenvolvidas como contribuição para o trabalho do designer na EaD. A pesquisa foi desenvolvida junto a designers da Coordenadoria Geral de Tecnologias Educacionais (CGTE) do Centro de Referência em Formação e em Educação a Distância (Cefor) do Instituto Federal do Espírito Santo (Ifes). Essas diretrizes foram desenvolvidas na pesquisa intitulada: O estudo da dimensão social do design sustentável como estratégia para o trabalho do designer na Educação a Distância, da qual resultou este artigo.

Palavras Chave: Design Social; Educação a Distância; Design.

\begin{abstract}
Distance Education (EaD) presents itself as an area for the performance of the designer, a field still little explored, and an area with great potential for growth. For all this, it is understood that social design can become an important tool for the development of the work of the designer who works in the EaD. With this, the objective of this article is to present the social design guidelines developed as contribution to the designer's work in the EaD. The research was developed with designers of the General Coordination of Educational Technologies (CGTE) of the Reference Center for Training and Distance Education (Cefor) of the Federal Institute of Espirito Santo (Ifes). The development of these guidelines occurred in the research entitled The study of the social dimension of sustainable design as a strategy for the designer's work in Distance Education.
\end{abstract}

Keywords: Social Design; Distance Education; Design 


\section{Introdução}

Nos últimos anos, tanto no Brasil como no mundo, é possível observar um crescimento constante e gradual na modalidade Educação a Distância (EaD). Concomitantemente, o design tem se tornado uma ferramenta cada vez mais transdisciplinar e importante em diversas áreas do conhecimento de forma similar também na educação.

Paralelamente, desde a década de 1990 tem se intensificado o questionamento acerca da função social do design (em todas as suas formas) em um mundo globalizado, em crise ecológica e com mudanças aceleradas na comunicação, economia, política e cultura (BRAGA, 2011).

Assim, o design "foi, e é essencialmente social na medida em que sua finalidade é o projeto para outrem e que foi e é fruto dessas aspirações" (BRAGA, 2011, p. 11). Nesse sentido, tem o dever de melhorar a qualidade de vida do ser humano, ideia defendida por Papanek ${ }^{1}$ (1923 - 1998) desde a década de 70, o qual argumenta que, como "designers ativos que somos, sabemos hoje que fazer unicamente aquilo que nos pedem - ou seja, obedecer ao cliente sem debater as questões morais e éticas inerentes ao que criamos - é a recusa última das responsabilidades do ser humano" (PAPANEK, 1977, p. 227).

Nesse contexto, surgiu a problemática em torno da interlocução de diferentes áreas do saber, entre elas o design e a educação, cuja discussão começou na pesquisa intitulada: O estudo da dimensão social do design sustentável como estratégia para o trabalho do designer na Educação a Distância (EaD), da qual resultou este artigo (SILVA, 2014).

Este artigo, assim, apresenta a instituição na qual essa pesquisa foi desenvolvida, detalhes das entrevistas feitas com os designers e o checklist com os princípios do design social, identificados na pesquisa e que podem ser utilizados pelos designers que atuam na EaD.

Objetiva-se mostrar que é possível tornar a educação a distância uma modalidade de ensino mais inclusiva, facilitando o acesso ao conhecimento e a formação profissional. Porém, é necessário adequar não só os fundamentos teóricos, mas também as práticas do chamado design social aos modelos desenvolvidos nas instituições de ensino que ofertam cursos na modalidade a distância, considerando a ótica dos princípios do design social, sobretudo, o aluno e o meio econômico e cultural em que se encontra inserido.

\section{Metodologia}

Este artigo deriva de uma pesquisa de natureza qualitativa, do tipo estudo de caso. Esse método é caracterizado como "uma pesquisa empírica que investiga um fenômeno contemporâneo dentro de seu contexto real, especialmente quando os limites entre o fenômeno e o contexto não são claramente evidentes" (YIN, 1994, p. 13).

A base teórica da pesquisa envolveu uma revisão bibliográfica, abordando temas relacionados à pesquisa, a fim de nivelar os conceitos e definições pertinentes ao Design Sustentável: dimensão social, Design Instrucional, Educação a Distância e Métodos de Design.

\footnotetext{
${ }^{1}$ Papanek foi professor no The Cooper Union em Nova York e no Instituto de Tecnologia de Massachusetts. Além de sua carreira como designer de produtos, ele também foi professor e autor com um interesse em arquitetura e antropologia. Com uma consideração pensativa, ele aplicou suas pesquisas e experiências para projetar ferramentas destinadas a melhorar a qualidade de vida nos países em desenvolvimento em todo o mundo. Disponível em: <http://vjpsocialdesign.madmuseum.org/about/>. Acesso em: 20 fev. 2018
} 
A revisão bibliográfica desses temas alicerçou o desenvolvimento da pesquisa, constituindo-se uma fase muito importante, pois possibilitou identificar os métodos de design que podem ser explorados e analisados de forma a contribuir com a proposta de diretrizes que atendam às características e que contribuam com a dimensão social do design sustentável no trabalho do designer na EaD.

Na segunda etapa do trabalho desenvolveu-se o estudo de caso. Nessa fase foram feitas coletas e análise de dados por meio de:

I - Observação do ambiente do setor de produção de materiais para observar seu funcionamento e/ou organização e forma de trabalho da equipe. Segundo Michel (2009), a observação não consiste apenas em ouvir e ver, mas também no exame dos fatos ou fenômenos que estão sendo estudados.

II - Entrevistas semiestruturadas com designers do Setor de Produção de Materiais para extrair deles a ideia de design social, se eles o aplicam no dia a dia de trabalho, se não aplicam, e se é possível aplicar.

O objetivo dessa etapa foi investigar e descrever o Cead/Ifes e a metodologia de trabalho dos designers do Setor de Produção de Materiais.

A terceira etapa objetivou propor princípios de design social com foco na EaD como contribuição para o trabalho do designer.

\section{Centro de Referência em Formação e em Educação a Distância (Cefor)}

O Centro de Educação a Distância (Cead), atualmente Centro de Referência em Formação e em Educação a Distância (Cefor) do Instituto Federal do Espírito Santo (Ifes), é uma instituição pública com ações voltadas para a Educação a Distância (EaD) e a formação de profissionais da área de educação.

Em 2005, com a criação, pelo Ministério da Educação (MEC), da Universidade Aberta do Brasil (UAB), um grupo de professores se uniu para elaborar uma proposta de projeto pedagógico para um curso da área tecnológica a ser ofertado na modalidade a distância e submeteu o projeto ao primeiro edital de oferta de cursos abertos pela UAB (COSTA JUNIOR, et al, 2010a).

Para confirmar esse primeiro curso, já aprovado pelo edital da UAB e cuja oferta estava prevista para 2007, criou-se, então, o Cead. Desde sua criação, ele é o responsável pelas ações de institucionalização da EaD e pela capacitação dos profissionais inseridos nessa modalidade de ensino, além de produzir materiais instrucionais e de infraestrutura, para o Ifes $^{2}$.

Atualmente, o Cefor está presente em 37 polos, com quatro cursos de pós-graduação, três de graduação, seis técnicos e diversos cursos de extensão. Para gerenciar todos esses cursos o Cefor conta com 41 servidores efetivos, sendo 18 técnicos administrativos, 23 professores e 12 estagiários, bolsistas e prestadores de serviço. Todos esses servidores estão distribuídos em diversas coordenações, mas o foco da pesquisa foi a Coordenação Geral de Tecnologias Educacionais (CGTE), mais especificamente os designers que compõem a equipe.

\footnotetext{
${ }^{2}$ Disponível em: <www.cefor.ifes.edu.br>. Acesso em: 12 dez. 2017.
} 


\section{Desenvolvimento da proposta das diretrizes de design social para a EaD}

A CGTE é composta por três setores: design gráfico, audiovisual e design instrucional, cuja equipe é composta por seis servidores, quatro bolsistas e seis estagiários, totalizando 16 colaboradores. Desses, nove são designers de formação, em formação ou estão desenvolvendo essa função dentro da equipe. Esses nove profissionais são os sujeitos da pesquisa e serão tratados por nomes fictícios.

Dos nove entrevistados, dois são estagiários e estão cursando Desenho Industrial com ênfase em Programação Visual, na Universidade Federal do Espírito Santo (UFES), e serão tratados como Eros e Antônio. Quatro são formados em Desenho Industrial, também pela UFES, sendo que uma é a pesquisadora e também possui formação em Design de Produto, Geise é bolsista, Clara e Luís são servidores. Bruna, cuja formação é desenho e plástica, pela Universidade Federal de Santa Maria (UFSM), é servidora e desenvolve atividades de designer, além de ser, atualmente, a coordenadora da equipe de design. Integram a equipe mais dois bolsistas: Guilherme, com formação em Design de Produto, pela Universidade de Vila Velha - (UVV); e Karla, formada em Desenho Industrial - Programação Visual, pela Universidade do Estado de Minas Gerais (UEMG).

Com o intuito de inserir o tema da pesquisa e observar se os entrevistados tinham alguma ideia do tema, a primeira pergunta foi: Para você, o que é design social?

De forma geral, todos tinham uma ideia do que era design social, o que permitiu que a entrevista prosseguisse sem a necessidade de uma explicação prévia sobre o tema. Entre as respostas dadas, destacou-se ${ }^{3}$ :

É quando você pensa no design, mas pensa de uma forma geral, não pensando somente na parte do design, não só fatos estéticos, pensar num todo (Karla, bolsista, informação verbal).

A fala de Karla complementa o que Geise definiu como conceito de design social, porque ter preocupações apenas estéticas pouco contribui para perceber a demanda do coletivo, conforme descreveu Geise:

Eu acho que é pensar no design como resolução de problemas, assim, a partir de um problema, a partir de uma demanda, de uma necessidade, você apresentar soluções para esta demanda para esta necessidade; e aí o design social seria olhar pra essa necessidade, essa demanda de um coletivo, de um grupo que estaria marginalizado, você não pensar em uma coisa comercial, e sim no aspecto humano, isso seria trabalho social, seria fazer esse trabalho para uma instituição ou grupo que não tenha fim puramente comercial (Geise, bolsista, informação verbal).

Já Guilherme direcionou sua resposta para a área da pesquisa, nesse caso, a EaD:

\footnotetext{
${ }^{3}$ Cabe aqui ressaltar que as passagens que estão em itálico se referem à transcrição das entrevistas e não foi feita qualquer correção gramatical. As únicas inferências foram: selecionar os trechos, omitir algumas palavras ou sentenças que comprometeriam seu entendimento e omitir nomes próprios (de pessoas, instituições, estados, cidades e bairros)
} 
É pensar no cunho social que a profissão de design tem, como a EaD que tem o papel de levar a educação com a ajuda do designer pode definir o que é design social (Guilherme, bolsista, informação verbal).

A pergunta seguinte versou sobre : Você acredita que pratica o design social no dia a dia em seu trabalho? Caso a resposta fosse não, haveria uma terceira pergunta: Para você, é possível incluir o design social em seu trabalho? Como? Por quê? Como todas as respostas às perguntas anteriores foram sim, não foi necessário fazer a pergunta número três. Assim, destacaram-se as seguintes respostas:

No dia a dia, eu acho que em parte, em parte sim, é porque a gente sempre, na hora de pensar o planejamento da disciplina, a gente sempre tem como foco o aluno que é o nosso público e de tentar levar as informações da melhor maneira possível para que ele possa compreender aquele conteúdo, aprender aquele conteúdo e gerar conhecimento para o futuro dele; é, ao mesmo tempo, um incentivo que a gente sempre dá para os nossos professores de sempre tentar trabalhar com conteúdos ou com exemplos que sejam do dia a dia, que sejam relacionados à vida dele para que eles possam realmente compreender a situação do dia a dia que ele tá vivendo. Então, não é diretamente o meu trabalho, mas as orientações que são dadas, o olhar que a gente tem sobre o planejamento dos professores é sempre com foco no aluno, sempre com foco no nosso aluno, para que a gente possa levar um material de melhor qualidade, para que ele possa ser uma pessoa reflexiva, que ele possa compreender, possa ser crítico e que isso gere uma transformação na vida dele (Clara, servidora, informação verbal).

Para Geise,

Aqui nesta instituição sim, porque a gente está falando de uma instituição de ensino, uma instituição federal, então, eu acho que algumas características a gente pode pegar, acho que ele, por ele não ser comercial, a gente está tratando que uma instituição que, por si só, é um coletivo que não tem fins lucrativos, o propósito dele é puramente educacional para o crescimento do ser humano, então, acho que tem sim, acho que a gente pode intensificar sempre, mas no fundo, no fundo é bastante social, apesar dele não estar estampado, mas você consegue identificar características.

Segundo Mendoza et al. (2010), para construir um mundo mais justo, solidário e sustentável é importante considerar o caráter estratégico da educação, que devem ser as verdadeiras resoluções no tocante às políticas sociais que podem contribuir para combater as assimetrias sociais.

Nesse universo, a atuação do designer instrucional é imprescindível. Assim, a Figura 1 contém um mapa conceitual baseado no tema design instrucional, do capítulo sete do livro "Polidocência na EaD: múltiplos enfoques", de autoria de Mendoza, et al. (2010), e resume a abrangência do trabalho do designer instrucional. 


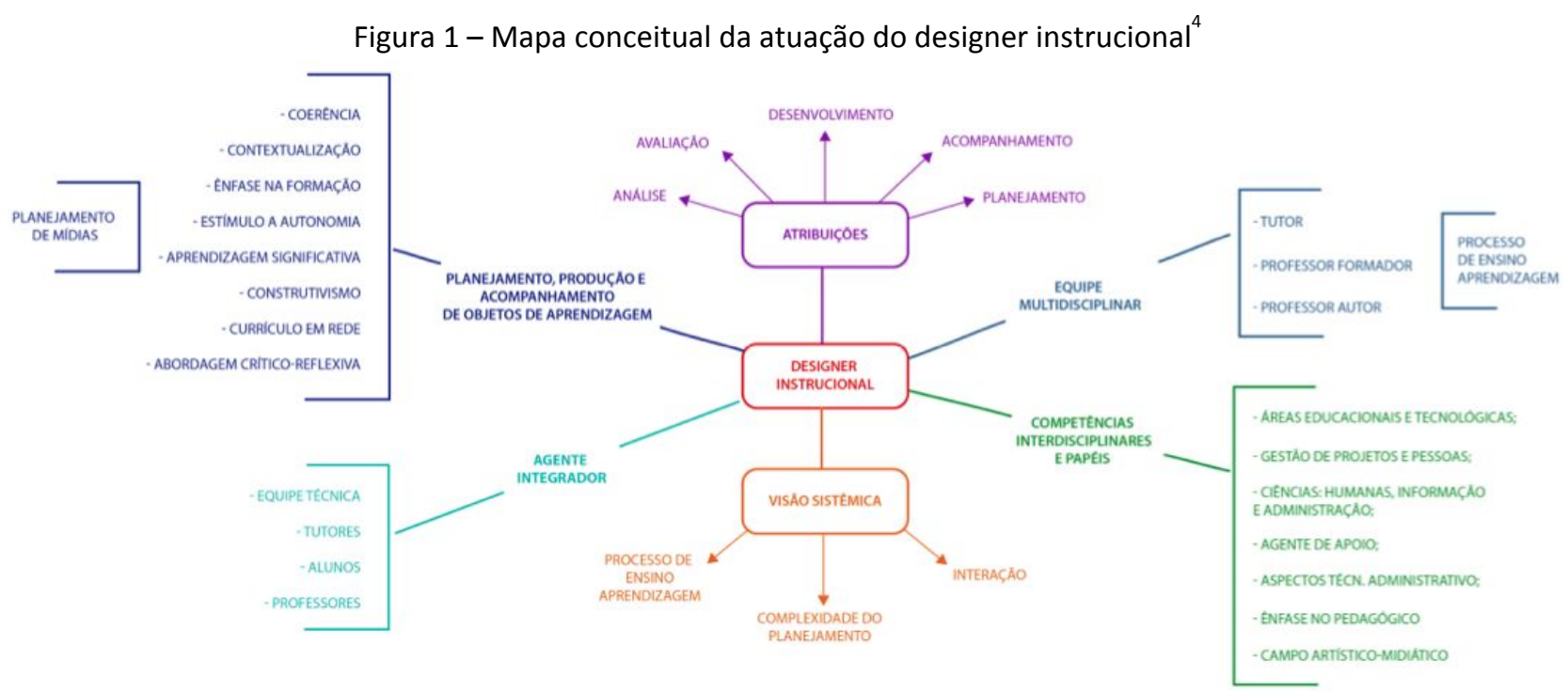

Fonte: autoria própria.

Porém, ao retirar a palavra instrucional do centro do mapa, com o intuito de confirmar as relações entre as áreas do design instrucional, design e design social, pode-se afirmar que esse mapa abrangeria qualquer trabalho do designer, independentemente de sua habilitação.

Para comprovar tal afirmação, durante a entrevista com os designers que compõem a equipe de produção de materiais, eles visualizaram esse mapa conceitual (Figura 1). Em seguida, deveriam responder se as informações constantes nele eram pertinentes ao trabalho que desenvolviam como designer, independentemente da formação pessoal, ou se eram específicas de uma área de formação.

Ao responder a pergunta, Clara disse:

Vejo todas, independente da área de atuação, eu acho que todas as atribuições, funções, eu acho que todas, talvez dependendo da formação, umas um pouco mais, talvez outras um pouco menos, mas de uma maneira geral, mesmo que seja pouco, mas está dentro da natureza do design.

Por outro lado, Antônio argumentou:

Bom, eu acho que engloba vários estilos de design, mas mais voltado para a educação, mas é bem amplo, são conceitos que a gente consegue englobar para design de produto, design gráfico pra várias áreas.

Para Geise,

os pontos são universais, as atribuições dos atores, as discriminações de cada um que variam de acordo com o projeto, pensando no design como um todo.

Assim como no mapa, no Quadro 1 delineiam-se as competências do designer instrucional desenvolvidas pelo International Board of Standards for Training, Performance and Instruction (IBSTPI) ${ }^{5}$, uma comissão internacional de pesquisadores que estuda e publica listas de

\footnotetext{
${ }^{4}$ Para mais detalhes sobre a construção deste mapa acesse:

http://anapaulanasta.com/wp-content/uploads/2015/01/Aline_Freitas.pdf

${ }^{5}$ Disponível em: <http://ibstpi.org/>. Acesso em: 1ㅇabr. 2018.
} 
competências e padrões de desempenho definidos para os profissionais das áreas de Educação, Desenvolvimento de Recursos Humanos e Tecnologias Educacionais.

Em 1986, o IBSTPI apresentou o primeiro conjunto de competências do design instrucional. A publicação foi o resultado de mais de um ano de pesquisa, discussão e validação por um grupo de profissionais de DI e acadêmicos. Desde o primeiro conjunto de competências houve muita coisa na prática, na tecnologia e no desenvolvimento das principais teorias que sustentam a área de design instrucional e, por isso, uma atualização dessa publicação foi publicada em 2000 e, mais recentemente, em 2012. Em cada revisão, novos elementos são incorporados ao processo, entre eles:

- A influência das tecnologias avançadas, design baseado em equipe e habilidades de gestão de negócios.

- Os fundamentos profissionais do design, bem como planejamento e análise, design e desenvolvimento e implementação e gestão de competências.

- A categorização de competências como essencial ou avançada.

- Uma representação maior de profissionais consultados em todo o mundo (incluindo diretores, especialistas e profissionais que participam da validação dos estudos).

Quadro 1 - Competências do Designer Instrucional.

\section{Fundamentos da Profissão}

1- Comunicar-se efetivamente, por meio visual, oral e escrito.

2- Aplicar pesquisas e teorias à prática de design instrucional.

3- Atualizar e melhorar conhecimentos, habilidades e atitudes referentes ao design instrucional e as suas áreas.

4- Aplicar coleta de dados e análise de competências em projetos de design instrucional.

5- Identificar e responder às implicações éticas, legais e políticas que surjam no trabalho de design instrucional.

\section{Planejamento e Análise}

6- Realizar uma avaliação das necessidades, a fim de recomendar soluções de design apropriadas e estratégicas.

7- Identificar e descrever a população-alvo e características ambientais.

8- Selecionar e usar técnicas de análise para determinar o conteúdo instrucional.

9- Analisar as características das tecnologias existentes e emergentes e seu uso potencial em um ambiente instrucional.

Design e Desenvolvimento 
10- Uso adequado do design instrucional e do processo de desenvolvimento para um determinado projeto.

11- Organizar programas e/ou produtos de avaliação e instrução a serem projetados e desenvolvidos.

12- Projetar intervenções instrucionais.

13- Planejar intervenções não instrucionais.

14- Selecionar ou modificar materiais instrucionais existentes.

15- Desenvolver materiais instrucionais.

16- Projetar avaliação da aprendizagem.

\section{Avaliação e Implementação}

17- Avaliar as intervenções instrucionais e não instrucionais.

18- Rever soluções instrucionais e não instrucionais baseado em dados.

19- Implementar, divulgar e difundir intervenções instrucionais e não instrucionais.

\section{Gestão}

20- Aplicar habilidades de negócios para gerenciar a função de design instrucional.

21- Gerenciar parcerias e relações de colaboração.

22- Planejar e gerenciar projetos de design instrucional.

Fonte: www.ibstpi.org. Acesso em: 22 de fev. de 2018.

Ao analisar tanto a Figura 1 quanto o Quadro 1, é possível identificar a universalização dessas competências, sendo que podem ser observadas no designer instrucional e também no designer, e até mesmo no designer social. Essa afirmação torna-se mais evidente ao visualizar a divisão dessas competências em: fundamentos da profissão, planejamento e análise, design e desenvolvimento, avaliação e implementação, e gestão, ou seja, contemplam-se as etapas já descritas aqui como etapas comuns nos métodos e modelos projetuais do design instrucional, design e design social.

Para confirmar essa proposição, alterações mínimas foram feitas no Quadro 1, principalmente nos itens com a palavra instrucional, sendo, assim, eliminada.

O Quadro 2 a seguir contém as alterações, podendo-se observar que a exclusão dessa palavra não comprometeu o entendimento das competências, ou seja, não interferiu na análise dos entrevistados.

Quadro 2 - Competências do Designer

\section{Fundamentos da Profissão}

1- Comunicar-se efetivamente, por meio visual, oral e escrito.

2- Aplicar pesquisas e teorias à prática de design. 
3- Atualizar e melhorar conhecimentos, habilidades e atitudes referentes ao design e às suas áreas.

4- Aplicar coleta de dados e análise de competências em projetos de design.

5- Identificar e responder às implicações éticas, legais e políticas que surjam no trabalho de design.

\section{Planejamento e Análise}

6- Realizar uma avaliação das necessidades, a fim de recomendar soluções de design apropriadas e estratégicas.

7- Identificar e descrever a população-alvo e características ambientais.

8- Selecionar e usar técnicas de análise para determinar o conteúdo.

9- Analisar as características das tecnologias existentes e emergentes e seu uso potencial em um ambiente.

\section{Design e Desenvolvimento}

10- Uso adequado do design instrucional e do processo de desenvolvimento para um determinado projeto.

11- Organizar programas e/ou produtos de avaliação a serem projetados e desenvolvidos.

12- Projetar intervenções.

13- Planejar intervenções não instrucionais.

14- Selecionar ou modificar materiais existentes.

15- Desenvolver materiais.

16- Projetar avaliação da aprendizagem.

\section{Avaliação e Implementação}

17- Avaliar as intervenções.

18- Rever soluções baseados em dados.

19- Implementar, divulgar e difundir intervenções.

\section{Gestão}

20- Aplicar habilidades de negócios para gerenciar a função de design.

21- Gerenciar parcerias e relações de colaboração.

22- Planejar e gerenciar projetos de design.

Fonte: Adaptado de www.ibstpi.org. Acesso em: 22 fev. 2014

Sob o ponto de vista da entrevistada Bruna,

todos os pontos, todos eles, acho que em maior ou menor escala, a gente tenta aplicar na produção, tudo que tu listou aqui, a gente tenta colocar no design, algumas coisas, a gente tem mais facilidade do que outras, mas, a princípio, tudo a 
gente tenta colocar se você levar em consideração que a única artista sou, eu acho que estamos indo bem.

A argumentação de Bruna não somente confirma a afirmação, a ultrapassa, ao identificar que os designers da CGTE tentam aplicar essas competências em seu trabalho.

E, para a designer Clara:

Para mim, todos os pontos colocados aqui, independentemente da formação, da especialidade do designer, para mim, são etapas que ele vai precisar desenvolver ao longo do projeto que ele vai desenvolver, todos, sem tirar nem pôr.

Segundo Guilherme, essas:

São competências de qualquer design. Acho que se aplica a qualquer área.

Para Ricardo,

Algumas dessas competências poderiam estar ordenadas de forma diferente, mas isso não atrapalha a análise, que faz com que eu afirme que sim, essas competências, esses pontos são comuns para qualquer área do design, talvez, gestão não seja tanto porque ainda não se ensina empreendedorismo na maioria dos cursos de design, mas sim, são todos de qualquer design, os pontos que estão aqui.

As respostas dos entrevistados reforçam a presença de pontos importantes e comuns relacionados ao design instrucional, ao design e ao design social, e que eles são trabalhados na CGTE, embora de forma incipiente.

Desse modo, ao compilar e cruzar os dados coletados entre as entrevistas, o referencial teórico e o estudo de caso, pode-se afirmar que o design social constitiu-se uma importante ferramenta para o designer que atua na EaD.

Nessa perspectiva, ao ter como referência toda a discussão apresentada, tem-se como proposta os seguintes princípios sobre os quais o designer pode refletir no momento em que estiver desenvolvendo os recursos educacionais solicitados à CGTE do Cead/Ifes ou a qualquer designer que esteja trabalhando em educação, em especial com a modalidade a distância:

\section{$\square$ O material proposto atende ao maior número de alunos possível?}

Para responder a essa questão, vários outros pontos listados a seguir precisam ser considerados.

प Estão sendo observados: faixa etária, etnias/raça/cor, possíveis deficiências, entre outros?

Essa miscigenação é uma realidade brasileira e é relevante, pois o aluno precisa se enxergar no material didático, nas mídias etc. Ele precisa perceber que o recurso educacional apresentado contempla sua raça, sua idade, e também uma possível deficiência (caso possua alguma), ou seja, não privilegia um ou outro aluno.

\section{$\square$ É possível tornar o material (sala, mídia, MDI) acessível?}

Atualmente, os fascículos/livros produzidos pelo Cefor são disponibilizados pelo Cead no AVA em formato PDF, o que impede os leitores de tela utilizados por deficientes visuais de ler o material. 
Uma forma de tornar esse material acessivel seria diagramar no próprio AVA, em html, o que viabilizará a leitura para esses alunos.

口 O conteúdo disponibilizado em forma de imagem ou outro tipo de mídia é de uma cultura específica de um Estado ou país, ou seja, é culturalmente de fácil entendimento?

É importante que o designer contemple o contexto em que o aluno está inserido, por exemplo: o que é canjica em uma região do país, é outra coisa ou tem outro nome em outra; então, isso pode, além de não atender ao objetivo educacional proposto, confundir o aluno.

Foi observado o perfil socioeconômico-cultural e ambiental dos municípios nos quais o curso está inserido?

Entender esse perfil pode auxiliar o designer a definir o cenário de uma animação, por exemplo, ou até o tamanho da mídia ou outro produto educacional em construção, pois o aluno precisa ter condições tecnológicas de abrir ou não esse produto.

$\square$ Os recursos educacionais disponibilizados agregam valor ao conhecimento do aluno? Podem ajudá-lo a refletir sobre questões sociais, econômicas e culturais?

Deve-se evitar apenas inserir um recurso educacional para que o AVA fique mais bonito ou dê cor ao fascículo; é fundamental estabelecer uma ligação com o conteúdo estudado, que deve dialogar com os objetivos educacionais propostos e, consequentemente, contribuir para a estimular a reflexão no aluno.

$\square$ recurso midiático foi pensado para que os alunos com acesso restrito aos recursos tecnológicos possam acessá-lo?

É importante considerar que, mesmo com o avanço tecnológico, nem todos têm acesso à internet de alta qualidade, o que impede, por exemplo, o acesso do aluno a um vídeo de extrema qualidade técnica e, consequentemente, de maior tamanho. Deve haver um equilíbrio entre a qualidade técnica do recurso e a possibilidade de todos terem acesso o recurso disponibilizado.

Há uma contextualização do conteúdo abordado e do tipo de mídia utilizada com a realidade social dos locais em que os cursos estão inseridos?

Essa contextualização é importante para que o aluno consiga ver uma aplicação prática do conteúdo estudado, ou seja, o tema abordado faça parte do seu dia a dia.

Foi verificado se o recurso educacional disponibilizado tem conteúdo racista?

As instituições de ensino, sejam elas públicas ou privadas, devem primar por não estimular o racismo seja ele qual for. Para isso, é preciso sempre verificar como o conteúdo está sendo abordado/transmitido e, até mesmo, se há mensagens subliminares no conteúdo apresentado.

$\square$ O recurso educacional transmite mensagens que podem contribuir com a redução da discriminação?

Esse ponto vai ao encontro do anterior, pois, além da importância de não disponibilizar conteúdos racistas, é fundamental atentar-se ter cuidado para não divulgar mensagens preconceituosas e, também, para que sejam reduzidas as discriminações já existentes ou, ao menos, não incentivá-las.

$\square$ material sinaliza mensagens que podem contribuir para estimular reflexões sobre o meio ambiente e a sustentabilidade? 
Considerando as discussões a respeito desse tema, é importante que as instituições de ensino, seja por intermédio do professor ou do designer, proponham recursos educacionais incentivadores da reflexão sobre o meio ambiente e a sustentabilidade. Porém, isso deve ser feito dentro do âmbito do componente curricular em estudo, ou seja, o tema deve estar vinculado ao conteúdo do aluno, para que ter significado para ele.

\section{A mensagem está sendo transmitida da forma mais positiva possível, mesmo que o conteúdo seja forte ou polêmico?}

Existem diversas maneiras de apresentar assuntos polêmicos, como o câncer, por exemplo. Assim, é fundamental ter consciência de que o importante é a mensagem ser captada pelo aluno, e talvez uma forma mais branda de transmitir essa mensagem seja a mais eficiente.

Esses 12 princípios podem ser trabalhados em forma de checklist pelo designer ou pela equipe de design desenvolvedora de um recurso educacional. Porém, há outros pontos merecedores de destaque nessas discussões. Deve-se, também, nesse sentido, considerar que as instituições públicas de ensino têm o compromisso de democratizar o acesso à educação pública de qualidade. Significa disponibilizar não somente conhecimentos teóricos e obrigatórios nas matrizes curriculares, mas conhecimentos colaboradores no processo de transformação dessas pessoas, principalmente na reflexão sobre suas próprias atitudes e as dos outros, a terem oportunidades de acesso a trabalhos dignos e, consequentemente, à qualidade de vida. Dessa forma, pode-se dizer que a educação e todo seu contexto é extremamente social.

\section{Apontamentos Finais e Alguns Aspectos para Discussão}

A educação a distância não é uma modalidade de ensino recente, mas, na atualidade, o avanço e a ampliação da tecnologia foram fundamentais para expandi-la. Reflexo disso é a oferta crescente de cursos oferecidos, tanto por instituições privadas quanto por instituições públicas.

Porém, para atender de forma eficiente a essa demanda crescente, são necessários profissionais capacitados de diversas áreas para atuar nessa modalidade de ensino, sendo imprescindíveis os pedagogos, professores, administradores, programadores, designers e designers instrucionais.

Entre esses profissionais, destacam-se o designer instrucional e o designer. O primeiro encontra-se no início do processo, e é peça-chave para que o professor planeje sua disciplina e os recursos educacionais referentes a ela, de forma a alcançar os resultados desejados no processo de ensino e aprendizagem. O segundo está na ponta e é fundamental na construção desses recursos educacionais, principalmente, as mídias.

Nesse universo, podendo contribuir e enriquecer os resultados dos trabalhos desenvolvidos tanto pelo DI quanto pelo Designer, é possível inserir o design social, um profissional bastante utilizado como ferramenta em projetos sociais, ONGs, entre outros.

Deve-se considerar também que o design social abarca, entre outras acepções, a materialização de uma ideia por meio de análise, planejamento, execução e avaliação, que resultam em um conceito e na difusão de um conhecimento, visando influenciar o comportamento voluntário do público-alvo, para promover mudanças sociais. Assim, evidencia-se que o trabalho do design instrucional, do design e do design social estão entrelaçados, vínculos esses reforçados pelos seus modelos e métodos projetuais. 
Assim sendo, os designers atuantes na CGTE desenvolvem também atividades de design instrucional, além de eles poderem incluir em seu trabalho os princípios do design social para a $\mathrm{EaD}$ apresentados nesta pesquisa e/ou qualquer outro estudo a ser ainda desenvolvido e que tenha a EaD como foco.

Infere-se, também, pela análise de todos os aspectos abordados nesta investigação, tanto o relacionado ao referencial teórico quanto ao estudo de caso e às entrevistas, que o design social é uma importante ferramenta para o designer que atua na EaD.

Não houve, contudo, a pretensão de esgotar o assunto neste estudo; ao contrário, o objetivo é iniciar uma discussão ainda pouco explorada na literatura e, até mesmo, pelo designer em relação ao seu próprio dia a dia profissional. Assim, sugere-se como proposta para pesquisas futuras a aplicação e o monitoramento dessas diretrizes em um recurso educacional ou em quantos forem necessários, a fim de verificar a viabilidade de aplicá-las por meio de testes, bem como fazer ajustes e/ou acrescentar itens.

Outra proposta para pesquisas seria o desenvolvimento de uma metodologia projetual com foco na $\mathrm{EaD}$ e no design social, englobando questões pertinentes às três áreas: design instrucional, design e design social.

Enfim, o estudo foi apenas uma etapa direcionada às discussões que podem ser ainda mais exploradas na EaD e no design, bem como se tornar uma maneira de mostrar uma possibilidade de atuação do designer atualmente pouco explorada nas instituições de ensino promovedoras, tanto públicas quanto privadas, de cursos nas modalidades presencial e/ou a distância. 


\section{Referências}

COSTA JUNIOR, J. M. et al. A utilização de planos de testes como instrumento de qualidade na produção de salas do Moodle. In: Anais do XVI Congresso Internacional Abed de Educação a Distância. Foz do Iguaçu-PR, 2010a.

IBSTPI. Disponível em: <www.ibstpi.org>. Acesso em: 01 de abril de 2018. International Board of Standards for Training, Performance and Instruction) International Board of Standards for Training, Performance and Instruction - IBSTPI

MENDOZA, B.A.P.; et al. Designer Instrucional: Membro da polidocência na educação a distância. In: MILL, D.R.S.; RIBEIRO, L.R.C.; OLIVEIRA, M.R.G.(Orgs). Polidocência na Educação a Distância: múltiplos enfoques. São Carlos: EdUFSCAR, 2010. p. 95-110.

O papel social do design gráfico: história, conceitos \& atuação profissional/organizador Marcos da Costa Braga. - São Paulo: Editora SENAC São Paulo, 2011.

PAPANEK, Victor. Diseñar para El Mundo Real: ecología humana y cambio social. Madrid: H.Blume Ediciones, 1977.

SILVA, A. F. da. 2014. O Estudo da dimensão social do design sustentável como estratégia para o trabalho do designer na EaD. Dissertação de Mestrado em Design - Universidade do Estado de Minas Gerais, Programa de Pós-Graduação em Design (PPGD).

Yin, R. K. (1994). Pesquisa Estudo de Caso - Desenho e Métodos (2 ed.). Porto Alegre: Bookman. 